\title{
Effects of a multi-strain probiotic on growth, health, and fecal bacterial flora of neonatal dairy calves
}

\author{
Yongqing Guo ${ }^{1,2, a}$, Zheng $\mathrm{Li}^{1,2, a}$, Ming Deng ${ }^{1,2}$, Yaokun $\mathrm{Li}^{1,2}$, Guangbin Liu ${ }^{1,2}$, \\ Dewu Liu ${ }^{1,2}$, Qihong Liu ${ }^{3}$, Qingshen Liü ${ }^{1,2, *}$, and Baoli Sun ${ }^{1,2, *}$
}

\author{
* Corresponding Authors: \\ Qingshen Liu \\ Tel: +86-20-85280279, Fax: +86-20-85280740, \\ E-mail: liuqshen@scau.edu.cn \\ Baoli Sun \\ Tel: +86-20-85284816, Fax: +86-20-85280740, \\ E-mail: baolisun@scau.edu.cn \\ ${ }^{1}$ Guangdong Laboratory of Modern \\ Agricultural Science and Technology in \\ Lingnan, South China Agricultural University, \\ Guangzhou 510642, China \\ ${ }^{2}$ College of Animal Science, South China \\ Agricultural University, Guangzhou 510642, \\ China \\ ${ }^{3}$ Jiangsu Hengfengqiang Biotechnology Co., \\ Ltd, Nantong 226121, China \\ a Yongqing Guo and Zheng Li contributed \\ equally to this article. \\ ORCID \\ Yongqing Guo \\ https://orcid.org/0000-0002-7689-8561 \\ Zheng Li \\ https://orcid.org/0000-0003-1208-1541 \\ Ming Deng \\ https://orcid.org/0000-0002-1753-8910 \\ Yaokun Li \\ https://orcid.org/0000-0003-2279-5652 \\ Guangbin Liu \\ https://orcid.org/0000-0001-8208-7338 \\ Dewu Liu \\ https://orcid.org/0000-0002-2234-0861 \\ Qihong Liu \\ https://orcid.org/0000-0002-6556-1832 \\ Qingshen Liu \\ https://orcid.org/0000-0003-0620-4381 \\ Baoli Sun \\ https://orcid.org/0000-0002-5012-0671
}

Submitted Feb 22, 2021; Revised Apr 29, 2021; Accepted Jul 4, 2021
Objective: The aim of this study was to investigate the effects of dietary supplementation with a multi-strain probiotic (MSP) product containing of Bifidobacterium animalis, Lactobacillus casei, Streptococcus faecalis, and Bacillus cerevisiae on growth, health, and fecal bacterial composition of dairy calves during the first month of life.

Methods: Forty Holstein calves ( 24 female and 16 male) at $2 \mathrm{~d}$ of age were grouped by sex and date of birth then randomly assigned to 1 of 4 treatments: milk replacer supplementation with $0 \mathrm{~g}$ (0MSP), $2 \mathrm{~g}$ (2MSP), $4 \mathrm{~g}$ (4MSP), and $6 \mathrm{~g}$ (6MSP) MSP per calf per day.

Results: Supplementation of MSP did not result in any significant differences in parameters of body measurements of calves during the $30 \mathrm{~d}$ period. As the dosage of MSP increased, the average daily gain $(p=0.025)$ and total dry matter intake $(p=0.020)$ of calves showed a linear increase. The fecal consistency index of the 2MSP, 4MSP, and 6MSP group calves were lower than that of the 0MSP group calves $(p=0.003)$. As the dosage of MSP increased, the concentrations of lactate dehydrogenase $(p=0.068)$ and aspartate aminotransferase $(p$ $=0.081)$ in serum tended to decrease, whereas the concentration of total cholesterol increased quadratically $(p=0.021)$. The relative abundance of Dorea in feces was lower $(p=0.011)$ in the 2MSP, 4MSP, and 6MSP group calves than that in the 0MSP group calves. The relative abundance of Dorea $(\mathrm{p}=0.001)$, Faecalibacterium $(\mathrm{p}=0.050)$, and Mitsuokella $(\mathrm{p}=0.030)$ decreased linearly, whereas the relative abundance of Prevotella tended to increase linearly as the dosage of MSP increased ( $\mathrm{p}=0.058$ ).

Conclusion: The MSP product can be used to reduce the diarrhea, improve the performance, and alter the composition of the fecal bacteria in neonatal dairy calves under the commercial conditions.

Keywords: Calf; Diarrhea Rate; Fecal Bacterial Flora; Performance; Probiotic

\section{INTRODUCTION}

Calf management is one of the most important tasks in dairy production, which requires a great deal of technology, equipment, and experience. In intensive dairy farm, calves are extremely susceptible to suffering enteric bacteria imbalance or gastrointestinal infection, which can cause lower digestion and absorption of nutrients, delayed growth, even diarrhea and dehydration [1]. The traditional practices employed by dairy farmers to treat diarrhea include using large quantities of antibiotics to combat invading pathogens or using electrolyte therapy to replenish lost fluids [2]. However, there has been great concern about the use of antibiotics which may result in antibiotic resistant pathogens, posing a potential risk of exposure for humans and calves [3]. The use of antibiotic in the feed of livestock was banned in European Union from 2006 and in China from July 1, 2020. Therefore, it is particularly important to find good alternatives to antibiotics, especially in preventing and 
treating diarrhea in calves and other young animals.

The number of bacteria in the gastrointestinal tract of neonatal calves is relatively small, and the balance of the bacteria can be easily damaged, especially when raising earlyweaned calves [4]. Under the guidance of the microecology theory, probiotics represent a kind of living bacterial preparation that produces growth-promoting substances, which is beneficial and harmless to the host [5]. Not only can probiotics reduce the occurrence of diseases, but also are able to improve the feed conversion rate and productive performance of livestock [6,7]. Various bacteria have been used as probiotics in ruminants, mainly including yeast $S$. cerevisiae, Lactobacillus spp., Bifidobacterium spp., Propionibacterium spp. [8]. The combination of Lactobacillus acidophilus and Bifidobacterium has been found to have positive effects on the immune function of lambs [9]. Probiotics can stimulate the production of mucus by intestinal goblet cells and are essential for protecting the host from colonisation and invasion by pathogens, as well as lubricating the intestinal epithelium [10]. Frizzo et al [11] reported that supplementing with lactic acid bacteria as a feed additive during the preweaning period can reduce the occurrence of diarrhea, improve average daily gain (ADG) and feed efficiency of dairy calves.

Supplementing beneficial bacteria to the feed of pig or poultry is not a new concept [12]. However, how to use live probiotics in the feed of young ruminants is rarely published and the results are inconsistent $[13,14]$. Therefore, the purpose of the current study was to determine whether supplementing a MSP product with Bifidobacterium animalis, Lactobacillus casei, Streptococcus faecalis, and Saccharomyces cerevisiae as a feed additive in milk replacers, can improve the growth, health, antioxidant capacity, and positively influence the microbiota of dairy calves during the first month of life.

\section{MATERIALS AND METHODS}

\section{Animal care}

The experimental design and procedure presented in this study were reviewed and approved by the Animal Care and Use Committee of the South China Agricultural University, Guangzhou, China (approval number SCAU\#2013-10).

\section{Feed additives}

An MSP product (Fengqiang Shengtai, Jiangsu Heng-fengqiang Biotechnology Co., Ltd, Nantong, China) was used in this study. It was composed of equal proportions of four live bacterial strains, namely Bifidobacterium animalis $\left(1.0 \times 10^{7}\right.$ colony-forming unit [CFU]/g), Lactobacillus casei $\left(1.0 \times 10^{7}\right.$ $\mathrm{CFU} / \mathrm{g})$, Streptococcus faecalis $\left(1.0 \times 10^{6} \mathrm{CFU} / \mathrm{g}\right)$, and Bacillus cerevisiae $\left(1.0 \times 10^{6} \mathrm{CFU} / \mathrm{g}\right)$. All the four stains are permitted as probiotics in the registration of ministry of agriculture of China (2014-101357037). The product was stored at $4^{\circ} \mathrm{C}$ and protected from light.

\section{Treatments}

Forty Holstein calves were divided into four homogenous groups according to sex (24 female and 16 male) and by date of birth. The four treatments differed depending on the feed additives, the four groups were as follows: control (0MSP, without feed additive), and the calves fed with $2 \mathrm{~g}$ (2MSP), 4 $\mathrm{g}(4 \mathrm{MSP})$, and $6 \mathrm{~g}$ (6MSP) per calf per day. All experimental feed additives were mixed into the reconstituted milk replacer immediately before morning feeding throughout the study.

\section{Animals and management}

The experiment was conducted at the Zhaoqing Wens dairy farm (Zhaoqing, Guangdong, China). This facility houses approximately 5,300 dairy cattle, 2,800 of which are milking cows. A total of 40 healthy Holstein calves (at $2 \mathrm{~d}$ of birth) were all obtained from the same farm. The calves separated from their dams within $2 \mathrm{~h}$ of birth and moved to a naturally ventilated barn with individual pens $(1.55 \mathrm{~m} \times 0.81 \mathrm{~m} \times 1.33$ $\mathrm{m}$; length $\times$ width $\times$ height), with leak board and bedded with dry straw for the duration of the trial. Calves were enrolled in the experiment over a period of 1 month from October to November 2019, and which were grouped by date of birth in separate rows for male and female. All calves were born within $24 \mathrm{~h}$ on the enrollment date (referred to as age $0 \mathrm{~d}$ ). The pens were refreshed every 3 days, and manure was removed daily to keep the bottom of pens dry and clean. The temperature of the calf barn was maintained at $21.5^{\circ} \mathrm{C} \pm 3.5^{\circ} \mathrm{C}$.

In the first $24 \mathrm{~h}$, calves received $6 \mathrm{~L}$ colostrum with a high concentration of immunoglobulins $(>50 \mathrm{mg} / \mathrm{mL}$ of immunoglobulin $\mathrm{G}[\mathrm{IgG}])$. On day 2, calves were fed transition milk (4 L/d divided into 2 equal feedings) at 7:00 AM and 6:00 PM. Calves were fed $4 \mathrm{~L}$ from $3 \mathrm{~d}$ to $10 \mathrm{~d}, 6 \mathrm{~L}$ from $11 \mathrm{~d}$ to $23 \mathrm{~d}, 8 \mathrm{~L}$ from 24 to $30 \mathrm{~d}$ of reconstituted milk replacer $(220 \mathrm{~g} / \mathrm{kg}$ crude protein [CP], $150 \mathrm{~g} / \mathrm{kg}$ ether extract, dry matter [DM] basic, $125 \mathrm{~g}$ powder as feed/L, Eurolac Blue, Netherlands) in 2 feedings at 07:00 and 18:00 until they were $30 \mathrm{~d}$ of age. The reconstituted milk replacer was heated between $39^{\circ} \mathrm{C}$ to $42^{\circ} \mathrm{C}$ before feeding. All calves consumed the same amount of milk replacer and had drinking water freely available. During the experiment, from d 3 to 30 , calves were fed ad libitum with pelleted starter feed $(265.9 \mathrm{~g} / \mathrm{kg} \mathrm{CP}, \mathrm{DM}$ basic, Guangdong Wens Dairy Co. Ltd, Guangdong, China). The starter feed was delivered at 9:00 AM to allow at least $10 \%$ feed refusals, which were collected and weighed on an individual basis. The nutritional components of milk replacer are presented in Table 1, and the nutrients of starter feed were analyzed according to the Association of Official Analytical Chemists [15]. 
Table 1. Chemical composition of the milk replacer and starter feed

\begin{tabular}{lcc}
\hline Items & Milk replacer $(\%$ as fed) & Starter feed (\% DM) \\
\hline Dry matter & 94.80 & 86.69 \\
Crude protein & 22.00 & 26.59 \\
Ether extract & 15.00 & $\mathrm{ND}$ \\
Ash & 10.00 & 6.86 \\
Crude fiber & 0.20 & $\mathrm{ND}$ \\
Calcium & 0.90 & 0.92 \\
Phosphorus & 0.60 & 0.39 \\
\hline
\end{tabular}

DM, dry matter; ND, not determined.

\section{Feed intake and growth performance}

The amounts of starter feed offered and refused were recorded every day to calculate the individual total dry matter intake (TDMI; milk replacer and starter feed), ADG, and feed efficiency. The skeletal growth (heart girth, withers height, hip height, and hip width) were measured on $\mathrm{d} 3$ and $\mathrm{d} 30$ (before morning feeding) according to the method described by Khan et al [16]. Calves were scored for manure before morning feeding every day. The feces score was determined following Marcondes et al [17], according to a standard scoring procedure $(0=$ normal feces; $1=$ semi-formed feces; $2=$ loose feces; and 3 = watery feces) by two students who were blinded to the experimental groups and trained by a veterinary practitioner. Diarrhea was considered when the feces score was $\geq 2$. The onset and duration of diarrhea in all calves were recorded. The diarrhea rate was calculated according to the procedure described by Sun et al [18], and formula is given as: Diarrhea rate $=$ (number of calves with diarrhea $\times$ days of diarrhea) / (total number of calves $\times$ examined days) $\times 100$. The fecal consistency index (FCI) proposed by Marcondes et al [17] was employed. The FCI was calculated at different stages of the experiment to judge the softness versus hardness of feces, as follows:

$$
\mathrm{FCI}=\frac{(\mathrm{dE} 1 \times 1)+(\mathrm{dE} 2 \times 2)+(\mathrm{dE} 3 \times 3)+(\mathrm{dE} 4 \times 4)}{\operatorname{Td} \times 4}
$$

In the formula, $\mathrm{dE} 1, \mathrm{dE} 2, \mathrm{dE} 3$, and $\mathrm{dE} 4$ represent the days when the feces score was 1,2,3, and 4, respectively. $\mathrm{Td}$ represents the test evaluation days.

Calf health was monitored daily by a veterinarian unaware of the treatments during the experimental period. Calves of 0MSP with diarrhea were treated with the standard procedure prescribed by the veterinarian, $3 \mathrm{~mL} 10 \%$ oxytetracycline (Eastern Along Pharmaceutical Co., Ltd., Foshan, China) injected intramuscularly before morning feeding. Calves in the 2MSP, 4MSP and 6MSP groups were only fed with MSP, and no drug treatments were administered. No calves had pneumonia or died during the experimental period.

\section{Blood sampling and analysis}

Before morning feeding at 30 days of age, $10 \mathrm{~mL}$ of blood was collected by jugular puncture of each calf using a vacuum coagulation-promoting vessel and the blood samples were centrifuged at 3,000 r/min for $15 \mathrm{~min}$. Serum was separated and partitioned into $1.5 \mathrm{~mL}$ aliquots and stored at $-80^{\circ} \mathrm{C}$ for further analyses. Test kits developed by Zhongsheng North Holding Biotechnology Co. Ltd (Beijing, China) were used to determine the content of glucose (GLU), total cholesterol (TC), uric acid, urea, creatinine, total protein, globulin, albumin, and the activity of lactate dehydrogenase (LDH), alanine aminotransferase, aspartate aminotransferase (AST), and alkaline phosphatase. The levels of total antioxidant capacity, malonaldehyde (MDA), superoxide dehydrogenase, and glutathione peroxidase in serum were tested with colorimetric assay kits (Nanjing Jiancheng Bioengineering Institute, Jiangsu, China) following the manufacturer's instructions, using visible recording spectrophotometer (V-T3, Yipu Corp, China). The levels of IgA, IgM, and IgG were tested with enzymelinked assay kits (Shanghai Ketao Biotechnology Centre, Shanghai, China) following the manufacturer's instructions, using an enzymatic analyzer (Rayto RT-6100, Rayto Corporation, Shenzhen, China).

\section{Feces sampling and analysis}

The fresh feces of each calf were collected with disposable sterile gloves by stimulating the rectum before morning feeding at 30 days of age. The samples were divided into $2 \mathrm{~mL}$ cryopreserved tubes and placed in liquid nitrogen. The samples were taken back to the laboratory and stored at $-80^{\circ} \mathrm{C}$ for analysis of fecal microflora.

Thirty-nine fecal samples (10 samples in each group, except that 9 samples in 2MSP group) were taken out of the refrigerator at $-80^{\circ} \mathrm{C}$ and thawed in ice water, and the whole process of aseptic operation was performed. Total genomic DNA was extracted from fecal samples using an EZNA DNA kit (Omega M5635-02, Norcross, GA, USA) following the manufacturer's instructions. A NanoDrop ND-1000 System (Thermo Fisher, Wilmington, DE, USA) was used to measure the concentration of DNA. Total DNA was then diluted to a final concentration of $20 \mathrm{ng} / \mu \mathrm{L}$ and stored at $-20^{\circ} \mathrm{C}$ until analysis. The V3-V4 region of the $16 \mathrm{~S}$ rRNA gene was amplified using the following primers: F (5'-ACTCCTACG GGAGGCAGCA-3') and R (5'- GGACTACHVG GGTW TCTAAT-3'). The total reaction volume of $25 \mu \mathrm{L}$ comprised $2 \mu \mathrm{L}$ of $2.5 \mathrm{mM}$ dNTPs, $5 \mu \mathrm{L}$ of $5 \times$ reaction buffer, $0.25 \mu \mathrm{L}$ of Q5 DNA polymerase, $1 \mu \mathrm{L}$ of each primer, $2 \mu \mathrm{L}$ of DNA template, and $2 \mu \mathrm{L}$ of $\mathrm{ddH}_{2} \mathrm{O}$. The real-time polymerase chain reaction (PCR) conditions were $98^{\circ} \mathrm{C}$ for $2 \mathrm{~min}$, followed by 20 to 35 cycles of denaturation at $98^{\circ} \mathrm{C}$ for $15 \mathrm{~s}$, and annealing and extension at $55^{\circ} \mathrm{C}$ for $30 \mathrm{~s}$ and at $72^{\circ} \mathrm{C}$ for $5 \mathrm{~min}$. All samples examined in this study provided complete DNA 
samples, as agarose gels clearly showed amplified products. After PCR amplification, amplicons were extracted from $2 \%$ agarose gels and purified using a Quant-iT PicoGreen dsDNA Assay Kit. Purified amplicons were operated using pairedend sequencing by Illumina MiSeq. The instructions of the platform and the manufacturer were from a commercial service provider (Personalbio, Shanghai, China). To ensure the sequencing quality, the optimal sequencing length of the target fragment was recommended to be $500 \mathrm{bp}$. All processes were carried out by the commercial service provider.

\section{Bioinformatics and statistical analysis}

The PANDAseq assembler was used to merge and repair overlapping double-ended Illumina fastq files. All sequences with low quality base call scores and sequences with unmodulated bases $(\mathrm{N})$ in the overlapped region were discarded. The fast file was then analyzed by the downstream computing pipeline of QIIME (2.0 version), an open-source software package, using the default minimum quality threshold of 25 . The chimerism sequences were detected using UCHIME algorithm (USEARCH 6.1) for ab initio and reference-based chimerism detection. Using the Greengenes database (version 13.5), sequences were clustered at the $97 \%$ sequence similarity level using operational taxonomic units (OTUs) collection method based on open reference, the QIIME algorithm and the USEARCH 6.1 method using the default parameters. Sequence quilt samples that failed to cluster were used for $a b$ initio OTU removal. All selected OTUs were then aligned by PyNAST, and the FastTree method was used to construct the phylogenetic tree to calculate the UniFrac distance in QIIME. An RDP classifier was used to assign representative OTU to bacterial classification through QIIME, with a confidence threshold of 0.8 .

The data measured in the experiment were preliminarily sorted using Excel 2016 software, and analyzed as a completely randomized design using the generalized linear mixed models procedure of the SAS (version 9.4, SAS Institute Inc., Cary, NC, USA) via the following model: $Y_{\mathrm{ijk}}=\mu+T_{\mathrm{i}}+S_{\mathrm{k}}+\varepsilon_{\mathrm{ij}}$, where $Y_{\mathrm{ijk}}=$ the dependent variable value of the test cattle in different treatment groups; $\mu=$ population mean; $T_{i}=$ dietary treatment effect $(\mathrm{i}=1,2,3,4) ; \mathrm{S}_{\mathrm{k}}=$ sex effect $(\mathrm{k}=1,2)$; and $\varepsilon_{\mathrm{ij}}$ $=$ random error. All the above data were compared with Tukey's range test, and an orthogonal polynomial model was used to analyse the relationship between the linear increased of MSP and each corresponding index (overall, linear, and quadratic curve). Treatment effects were declared significant at $\mathrm{p}<0.05$, and the tendencies were from $\mathrm{p}>0.05$ to $<0.10$.

\section{RESULTS}

Intake and growth performance

There was no significant difference $(\mathrm{p}>0.05)$ in the body mea- surements parameters (ADG of body height, body length, chest girth, and cannon girth) among four treatments (Table 2). The body weight on $30 \mathrm{~d}(\mathrm{p}=0.071)$, ADG $(\mathrm{p}=0.077)$, starter feed intake $(\mathrm{p}=0.096)$ and TDMI $(\mathrm{p}=0.096)$ of calves showed an increasing trend, with increasing the dosage of MSP. Meanwhile, the body weight gain ( $p=0.085)$, ADG ( $p$ $=0.025)$, starter feed intake $(\mathrm{p}=0.020)$, and TDMI $(\mathrm{p}=0.020)$ of calves showed linear increase as the dosage of MSP increased.

\section{Diarrhea incidence}

As shown in Table 3, compared with the 0MSP calves, the diarrhea rates of the 2MSP, 4MSP, and 6MSP calves were all reduced, from $70 \%$ for $0 \mathrm{MSP}$ to $10 \% 0 \mathrm{MSP}$ for $6 \mathrm{MSP}$. The FCI of the 2MSP, 4MSP, and 6MSP calves were lower ( $\mathrm{p}=$ 0.003 ) than the control group calves. However, there were no significant difference of FCI among the 2MSP, 4MSP, and 6MSP calves.

\section{Serum metabolites}

As the dosage of MSP increased, the concentrations of LDH $(\mathrm{p}=0.068)$ and AST $(\mathrm{p}=0.081)$ in serum tended to decrease, the concentration of LDH decreased linearly $(p=0.025)$, and the concentration of AST decreased quadratically $(\mathrm{p}=$ 0.015 ), whereas the concentration of TC increased quadratically $(\mathrm{p}=0.021)$ (Table 4$)$. Moreover, the concentration of TC in serum increased $(\mathrm{p}=0.043)$ significantly in 4MSP calves than the $6 \mathrm{MSP}$ calves. The other parameters of serum were not affected by dietary treatment.

\section{Serum antioxidant capacity and immunological parameters}

The treatments did not affect ( $p>0.05)$ any antioxidant or immunological parameters in the serum of four groups (Table $5)$. The contents of MDA were numerically lower $(p=0.130)$ in the 2MSP, 4MSP, and 6MSP calves than the 0MSP calves.

\section{Fecal microbiota analysis}

Diversity of fecal bacterial communities: A total of 5,205,474 sequences were obtained from 39 fecal samples sequenced in the V3-V4 region of the 16S rRNA gene on Illumina Miseq high-throughput sequencing platform, with an average of 133,474 sequences per sample. After the comparison, 4,668,610 valid sequences and 2,658,878 high-quality valid sequences were obtained. According to the $97 \%$ similarity, effective sequences were clustered into 44,759 OTUs. As shown in Figure 1 , there were 2,129 OTUs in the four groups, accounting for $4.76 \%$ of the total. There were 563 OTUs in the 2MSP, 4MSP, and $6 \mathrm{MSP}$ calves, accounting for $1.26 \%$ of the total. The OTU number and proportion of each group were 13,934 and 31.13\% in 0MSP, 14,170 for $31.66 \%$ in $2 \mathrm{MSP}, 16,617$ for $37.13 \%$ in $4 \mathrm{MSP}$, and 14,651 for $32.73 \%$ in $6 \mathrm{MSP}$. The unique OTU 
Table 2. Effect of MSP on the growth performance of calves

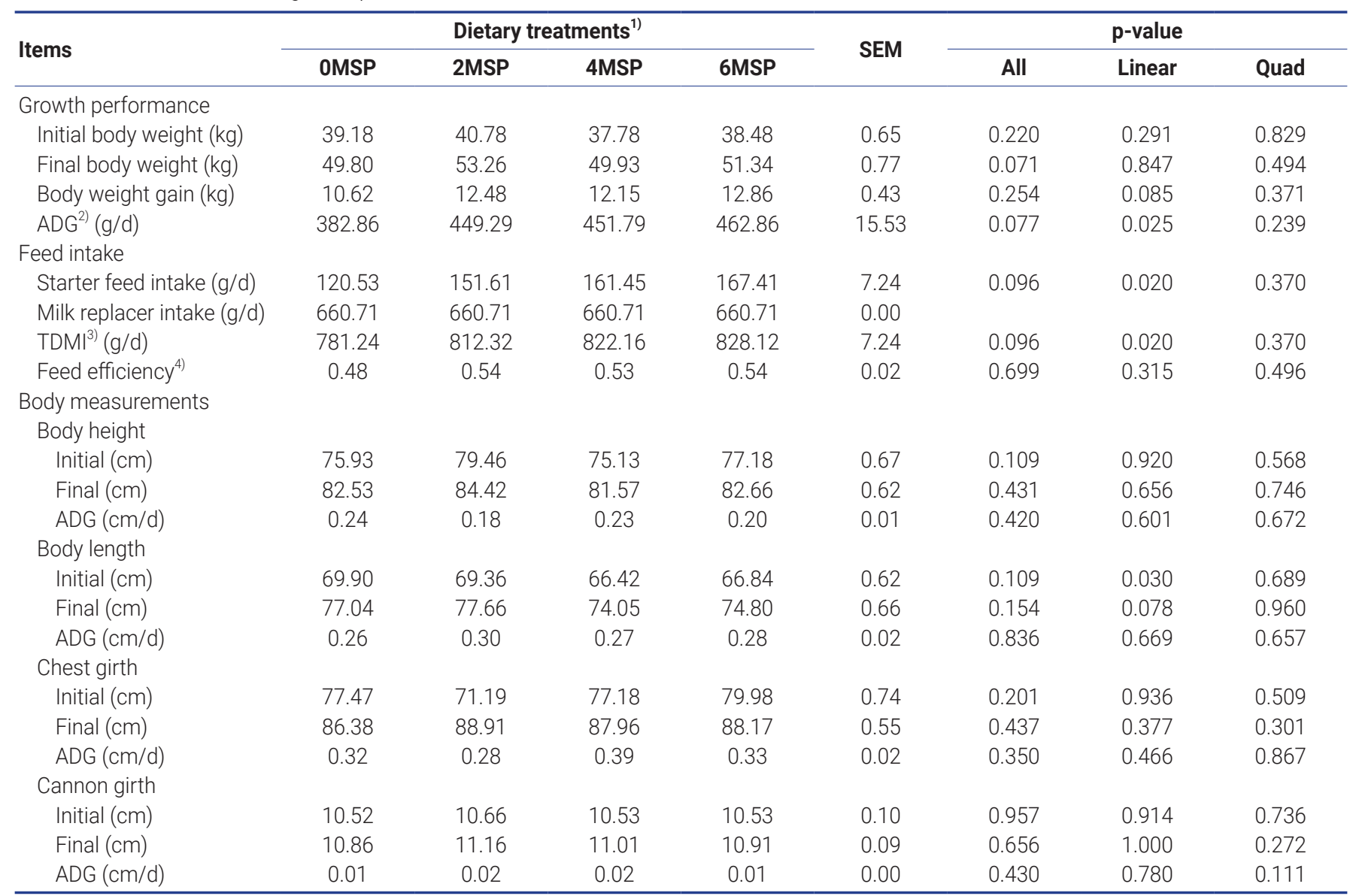

MSP, multi-strain probiotic; SEM, standard error of the mean; ADG, average daily gain; TDMI, total dry matter intake.

1) OMSP, 2MSP, 4MSP, 6MSP: a basal diet with 0, 2, 4, and $6 \mathrm{~g}$ MSP per calf per day, respectively.

2) $A D G$ = weight gain / number of days on feed.

${ }^{3)}$ TDMI, total dry matter intake of milk replacer and starter feed $(\mathrm{g} / \mathrm{d})$.

4) Feed efficiency $=\mathrm{g}$ ADG/g TDMI.

numbers of the four groups were $8,416,8,939,10,384$, and 8,937, respectively.

According to Table 6 and Figure 2, supplementation of MSP had no significant effect on the number of microbial diversity (Shannon, Chaol, Goods coverage, Observed species and Pielou-e). The 4MSP group exhibited the highest value in each index, indicating that the abundance and uniformity of intestinal bacteria in 4MSP were higher than the group 0MSP, 2MSP and 6MSP calves. As the dosage of MSP increased, the Shannon, Chaol and Observed species numeri- cally increased in the fecal microbe.

The contributions of the primary coordinates of the first (Axis1) and the second (Axis 2) were $9.6 \%$ and $6.1 \%$, respectively (Figure 3). The samples in 6MSP calves were distributed in a wide range, and the degree of polymerisation was relatively low, indicating that the environment of intestinal bacteria was significantly affected by the $6 \mathrm{MSP}$ treatment. The samples of OMSP were mainly distributed in the middle of the coordinate axis. As the dosage of MSP increased, the distribution of 2MSP, 4MSP and 6MSP was shifted, and the distance

Table 3. Effect of MSP on the diarrhea incidence of calves

\begin{tabular}{|c|c|c|c|c|c|c|}
\hline \multirow{2}{*}{ Items } & \multicolumn{4}{|c|}{ Dietary treatments $^{1)}$} & \multirow{2}{*}{ SEM } & \multirow{2}{*}{ p-value } \\
\hline & OMSP & 2MSP & 4MSP & 6MSP & & \\
\hline Diarrhea rate (\%) & 70.00 & 20.00 & 30.00 & 10.00 & 13.15 & - \\
\hline
\end{tabular}

MSP, multi-strain probiotic; SEM, standard error of the mean; $\mathrm{FCl}$, fecal consistency index.

1) OMSP, 2MSP, 4MSP, 6MSP: a basal diet with 0, 2, 4, and $6 \mathrm{~g}$ MSP per calf per day, respectively.

$a, b$ Mean values within a row with different superscripts differ significantly (Tukey's test; $p<0.05$ ). 
Table 4. Effect of MSP on the serum biochemical indexes of calves

\begin{tabular}{|c|c|c|c|c|c|c|c|c|}
\hline \multirow{2}{*}{ Items } & \multicolumn{4}{|c|}{ Dietary treatments } & \multirow{2}{*}{ SEM } & \multicolumn{3}{|c|}{$\mathrm{p}$-value } \\
\hline & OMSP & 2MSP & 4MSP & $6 \mathrm{MSP}$ & & All & Linear & Quad \\
\hline $\mathrm{GLU}(\mathrm{mmol} / \mathrm{L})$ & 4.10 & 3.79 & 4.07 & 3.82 & 0.10 & 0.596 & 0.537 & 0.881 \\
\hline $\mathrm{TC}(\mathrm{mmol} / \mathrm{L})$ & $2.40^{\mathrm{ab}}$ & $2.57^{\mathrm{ab}}$ & $3.03^{\mathrm{a}}$ & $2.30^{\mathrm{b}}$ & 0.10 & 0.043 & 0.863 & 0.021 \\
\hline $\mathrm{UA}(\mu \mathrm{mol} / \mathrm{L})$ & 56.23 & 53.13 & 52.83 & 55.13 & 1.75 & 0.895 & 0.826 & 0.462 \\
\hline UREA (mmol/L) & 3.62 & 3.64 & 3.16 & 3.76 & 0.12 & 0.343 & 0.956 & 0.247 \\
\hline $\mathrm{CR}(\mu \mathrm{mol} / \mathrm{L})$ & 73.04 & 83.34 & 72.64 & 70.54 & 2.28 & 0.148 & 0.335 & 0.146 \\
\hline $\mathrm{TP}(\mathrm{g} / \mathrm{L})$ & 56.99 & 55.10 & 56.51 & 57.94 & 0.85 & 0.692 & 0.577 & 0.333 \\
\hline $\operatorname{ALB}(\mathrm{g} / \mathrm{L})$ & 26.88 & 26.49 & 25.85 & 26.60 & 0.37 & 0.817 & 0.674 & 0.470 \\
\hline $\operatorname{GLOB}(\mathrm{g} / \mathrm{L})$ & 30.11 & 28.61 & 30.66 & 31.34 & 1.05 & 0.828 & 0.551 & 0.613 \\
\hline $\mathrm{LDH}(\mathrm{U} / \mathrm{L})$ & 938.49 & 802.99 & 819.09 & 778.69 & 24.74 & 0.068 & 0.025 & 0.273 \\
\hline $\operatorname{ALT}(\mathrm{U} / \mathrm{L})$ & 7.62 & 6.34 & 7.16 & 7.31 & 0.27 & 0.341 & 0.962 & 0.168 \\
\hline AST (U/L) & 45.42 & 36.01 & 36.72 & 42.02 & 1.49 & 0.081 & 0.464 & 0.015 \\
\hline $\operatorname{ALP}(\mathrm{U} / \mathrm{L})$ & 195.38 & 197.35 & 267.75 & 148.46 & 17.99 & 0.099 & 0.634 & 0.072 \\
\hline
\end{tabular}

MSP, multi-strain probiotic; SEM, standard error of the mean; GLU, glucose; TC, total cholesterol; UA, uric acid; UREA, urea; CR, creatinine; TP, total protein; ALB, albumin; GLOB, globulin; LDH, lactate dehydrogenase; ALT, alanine aminotransferase; AST, aspartate aminotransferase; ALP, alkaline phosphatase.

1) OMSP, 2MSP, 4MSP, 6MSP: a basal diet with 0, 2, 4, and $6 \mathrm{~g}$ MSP per calf per day, respectively.

$a, b$ Mean values within a row with different superscripts differ significantly (Tukey's test; $p<0.05$ ).

Table 5. Effect of MSP on the serum antioxidant index of calves

\begin{tabular}{|c|c|c|c|c|c|c|c|c|}
\hline \multirow{2}{*}{ Items } & \multicolumn{4}{|c|}{ Dietary treatments ${ }^{1)}$} & \multirow{2}{*}{ SEM } & \multicolumn{3}{|c|}{ p-value } \\
\hline & OMSP & $2 \mathrm{MSP}$ & 4MSP & 6MSP & & All & Linear & Quad \\
\hline $\mathrm{GSH}-\mathrm{Px}(\mathrm{U} / \mathrm{mL})$ & 161.48 & 159.00 & 148.87 & 167.66 & 5.67 & 0.504 & 0.831 & 0.234 \\
\hline $\mathrm{SOD}(\mathrm{U} / \mathrm{mL})$ & 52.34 & 56.10 & 54.99 & 53.51 & 2.67 & 0.949 & 0.912 & 0.589 \\
\hline T-AOC (U/mL) & 13.50 & 14.31 & 12.89 & 16.20 & 0.77 & 0.260 & 0.227 & 0.310 \\
\hline MDA (nmol/mL) & 5.52 & 4.49 & 5.06 & 5.00 & 0.10 & 0.130 & 0.466 & 0.110 \\
\hline $\lg A(\mu \mathrm{g} / \mathrm{mL})$ & $3,395.56$ & $3,472.93$ & $3,523.40$ & $3,331.33$ & 76.74 & 0.834 & 0.842 & 0.399 \\
\hline $\operatorname{lgG}(\mathrm{mg} / \mathrm{mL})$ & 15.75 & 16.20 & 16.89 & 16.67 & 0.49 & 0.854 & 0.444 & 0.742 \\
\hline $\operatorname{lgM}(\mu \mathrm{g} / \mathrm{mL})$ & $1,748.88$ & $1,716.88$ & $1,688.83$ & $1,703.82$ & 55.65 & 0.985 & 0.754 & 0.840 \\
\hline
\end{tabular}

MSP, multi-strain probiotic; SEM, standard error of the mean; GSH-Px, glutathione peroxidase; SOD, superoxide dehydrogenase; T-AOC, total antioxidative capacity; MDA, malonaldehyde; Ig, immunoglobulin.

1) OMSP, 2MSP, 4MSP, 6MSP: a basal diet with 0, 2, 4, and $6 \mathrm{~g}$ MSP per calf per day, respectively.

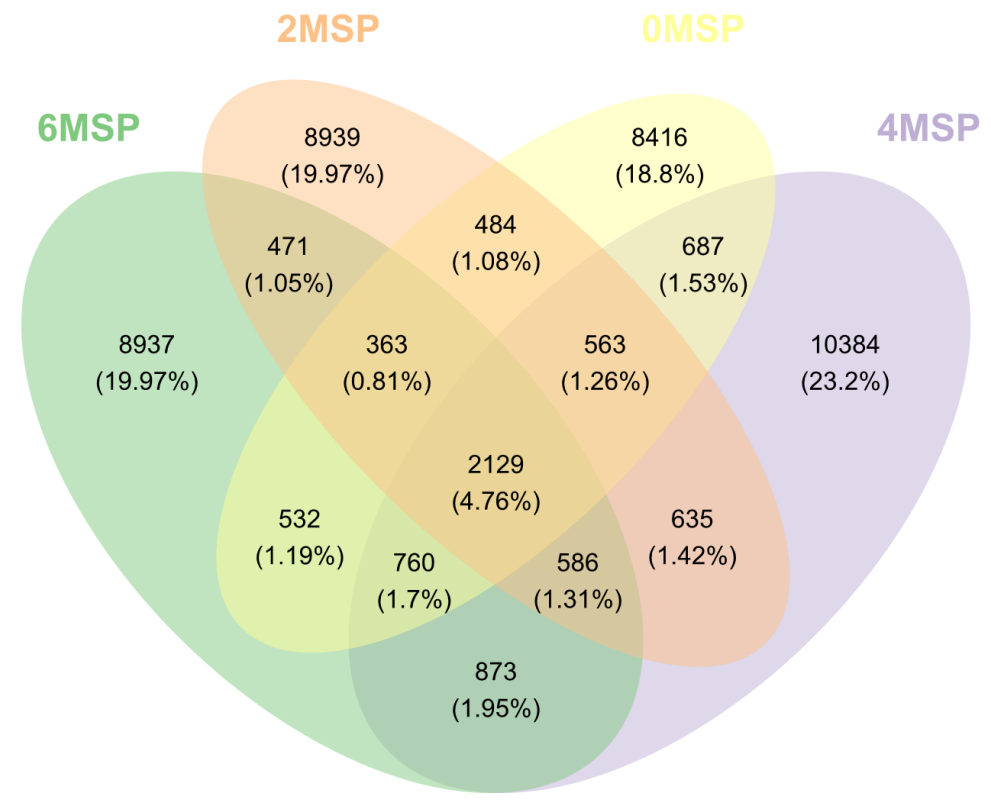

Figure 1. A Venn diagram analysis. A Venn diagram showing shared and unique OTUs at $97 \%$ identity among the four groups ${ }^{1)}$. OUT, operational taxonomic units; MSP, multi-strain probiotic. ${ }^{1)}$ OMSP, 2MSP, 4MSP, 6MSP: a basal diet with 0, 2, 4, and $6 \mathrm{~g}$ MSP per calf per day, respectively. 
Table 6. Effect of MSP on the community diversity (Alpha diversity) of fecal bacterial community of calves

\begin{tabular}{|c|c|c|c|c|c|c|c|c|}
\hline \multirow{2}{*}{ Items } & \multicolumn{4}{|c|}{ Dietary treatments ${ }^{1)}$} & \multirow{2}{*}{ SEM } & \multicolumn{3}{|c|}{ p-value } \\
\hline & OMSP & 2MSP & 4MSP & $6 \mathrm{MSP}$ & & All & Linear & Quad \\
\hline Shannon & 7.53 & 7.44 & 7.94 & 7.67 & 0.14 & 0.601 & 0.956 & 0.736 \\
\hline Chao1 & $2,154.22$ & 2,313.33 & $2,661.79$ & $2,506.75$ & 113.46 & 0.408 & 0.481 & 0.491 \\
\hline Pielou-e & 0.69 & 0.68 & 0.71 & 0.70 & 0.01 & 0.687 & 0.866 & 0.916 \\
\hline Observed species & $1,967.70$ & $2,025.04$ & $2,360.86$ & $2,186.93$ & 96.68 & 0.451 & 0.700 & 0.543 \\
\hline Goods coverage & 0.99 & 0.99 & 0.99 & 0.99 & 0.00 & 0.251 & 0.239 & 0.391 \\
\hline
\end{tabular}

MSP, multi-strain probiotic; SEM, standard error of the mean.

1) OMSP, 2MSP, 4MSP, 6MSP: a basal diet with 0, 2, 4, and $6 \mathrm{~g}$ MSP per calf per day, respectively.
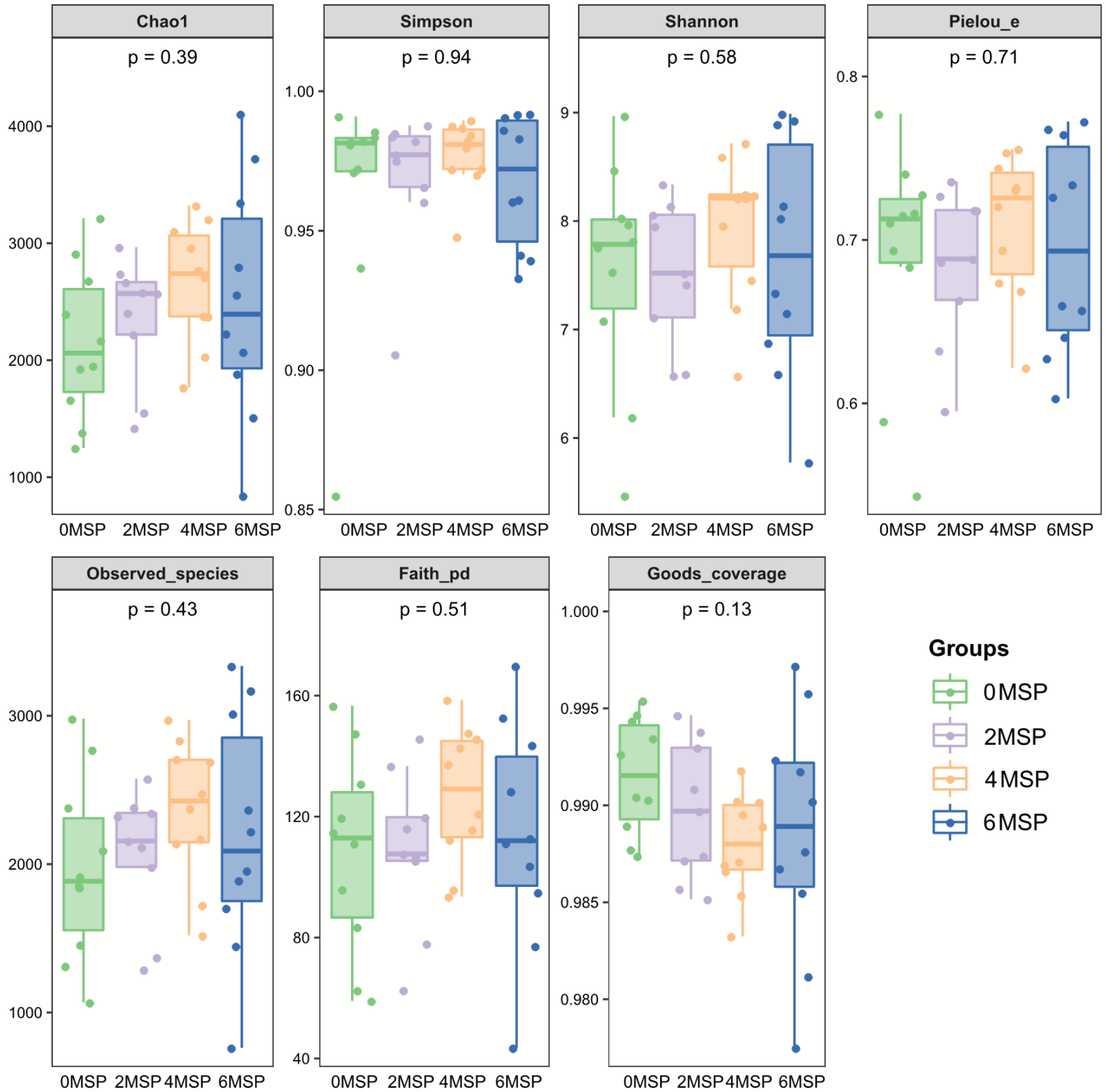

OMSP 2MSP 4MSP 6MSP

Figure 2. Bentobium plot of the fecal bacterial flora - diversity analysis index ${ }^{1)}$. ${ }^{1)}$ OMSP, 2MSP, 4MSP, 6MSP: a basal diet with 0, 2, 4, and $6 \mathrm{~g}$ MSP per calf per day, respectively. MSP, multi-strain probiotic. 


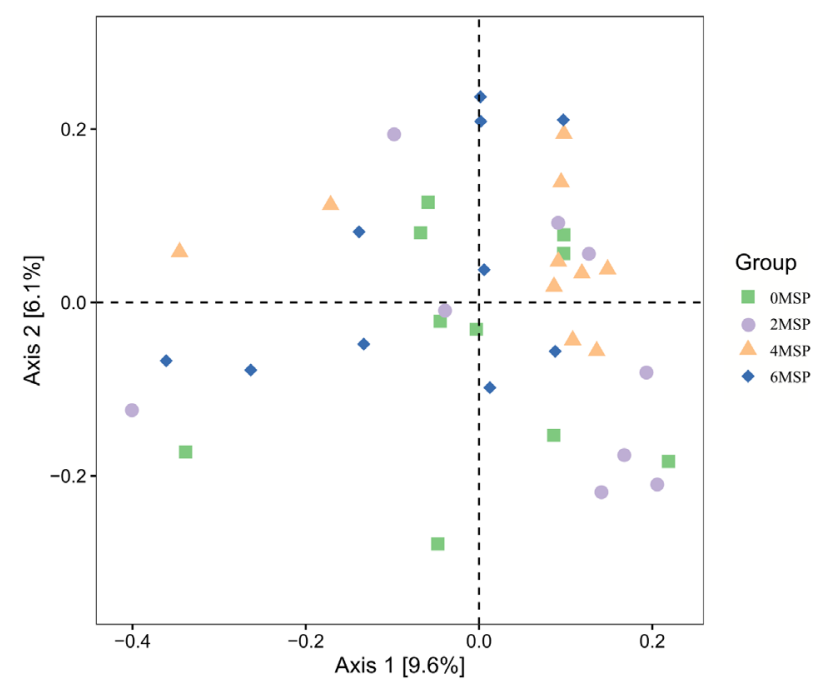

Figure 3. Principal coordinates analysis (PCoA) plots of fecal bacterial flora (Unweighted UniFrac) ${ }^{1)}$. ${ }^{1)}$ OMSP, 2MSP, 4MSP, 6MSP: a basal diet with 0, 2, 4, and $6 \mathrm{~g}$ MSP per calf per day, respectively. MSP, multi-strain probiotic.

between 2MSP and 4MSP was relatively close, indicating that the intestinal bacterial flora of these groups was more similar.

Fecal bacterial community structure: At the phylum level, a total of 11 phyla had a relative abundance of more than $0.01 \%$, among which four phyla had a relative abundance of more than 1\% including Bacteroidetes, Firmicutes, Actinobacteria, and Proteobacteria, with a relative abundance of $40 \%, 55 \%$,
$1 \%$, and $1 \%$, respectively (Figure 4 ). As shown in Table 7 , as the dosage of MSP increased, the relative abundance of Tenericutes tended to increase $(\mathrm{p}=0.092)$ at the phylum level and increased in a quadratic curve $(\mathrm{p}=0.023)$. However, there were no significant difference regarding the relative abundance of other phyla among the four groups.

At the genus level, as shown in Figure 5 and Table 8, the relative abundance of Dorea in the 2MSP and 6MSP calves were significantly lower $(\mathrm{p}=0.011)$ than the 0MSP calves, and the relative abundance of Faecalibacterium in the 2MSP was significantly lower $(p=0.045)$ than the 0MSP. As the dosage of MSP increased, the relative abundance of Dorea ( $\mathrm{p}$ $=0.001)$, Faecalibacterium $(\mathrm{p}=0.050)$, and Mitsuokella $(\mathrm{p}=$ 0.030 ) decreased linearly, whereas the relative abundance of Prevotella tended to increase linearly $(\mathrm{p}=0.058)$.

\section{DISCUSSION}

\section{Intake and growth performance}

The result of the present study indicated that the gut microbiota is closely related to the host health, and the consumption of probiotics has potential beneficial effects on the host [19]. Growth retardation of calves can influence the potential production performance of dairy cows, which is related to feeding management, higher morbidity and mortality, and increased breeding costs [20]. The increased of ADG was due to the higher starter feed and TDMI of MPS calves in our study. Probiotics can produce amylase, cellulase, protease and other substances, which will improve the digestive function of calves

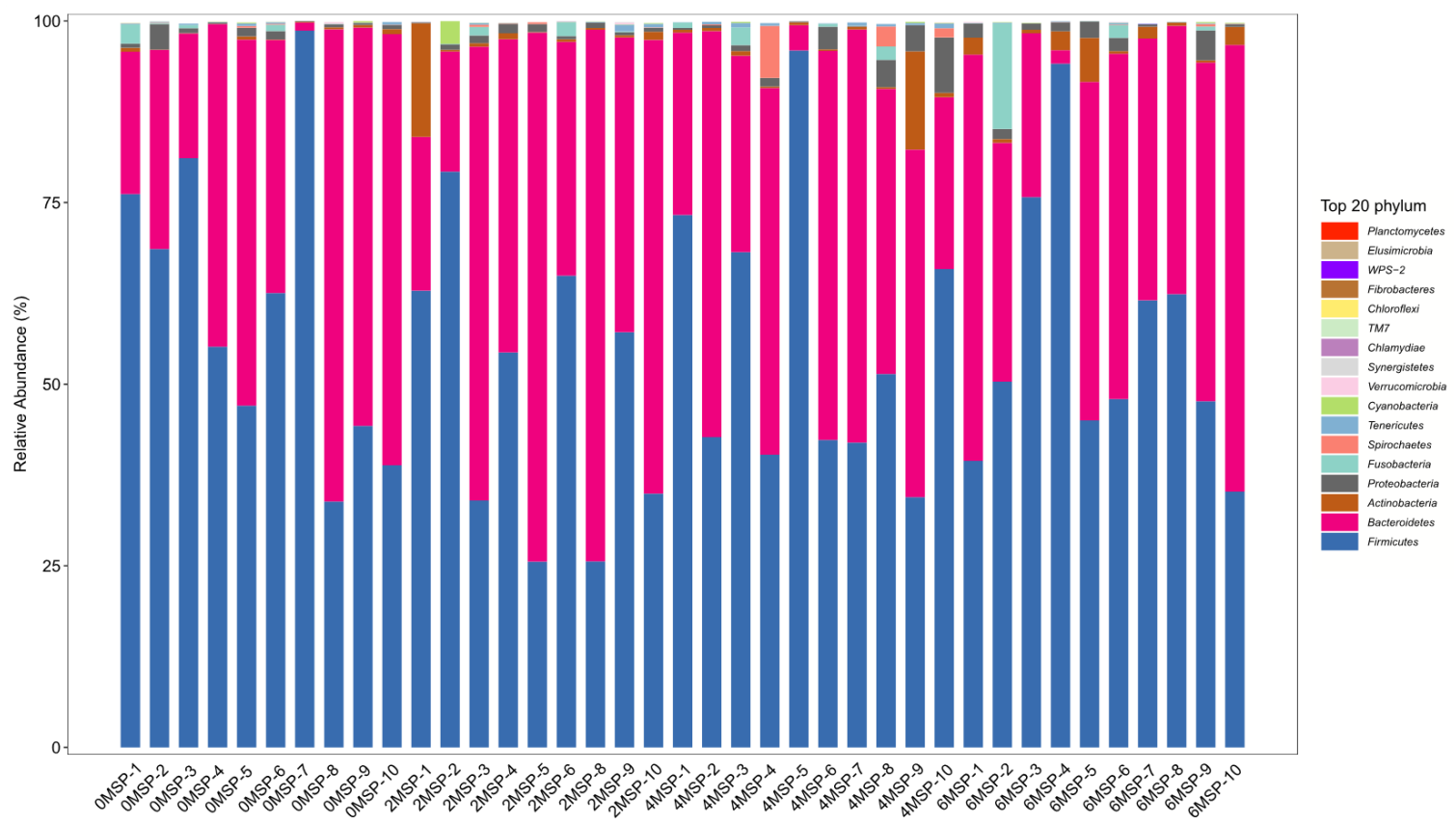

Figure 4. Fecal bacterial flora composition of dairy calves (phylum level, \%) ${ }^{1)} .{ }^{1)}$ OMSP, 2MSP, 4MSP, 6MSP: a basal diet with 0, 2, 4, and $6 \mathrm{~g}$ MSP per calf per day, respectively. MSP, multi-strain probiotic. 
Table 7. Effect of MSP on the relative abundance of fecal bacteria flora of calves (phylum level; \%)

\begin{tabular}{|c|c|c|c|c|c|c|c|c|}
\hline \multirow{2}{*}{ Phylum name } & \multicolumn{4}{|c|}{ Dietary treatments ${ }^{1)}$} & \multirow{2}{*}{ SEM } & \multicolumn{3}{|c|}{ p-value } \\
\hline & OMSP & $2 \mathrm{MSP}$ & 4MSP & $6 \mathrm{MSP}$ & & All & Linear & Quad \\
\hline Actinobacteria & 0.27 & 2.15 & 1.71 & 1.72 & 0.53 & 0.642 & 0.330 & 0.400 \\
\hline Cyanobacteria & 0.04 & 0.38 & 0.05 & 0.04 & 0.08 & 0.394 & 0.652 & 0.282 \\
\hline Firmicutes & 60.63 & 47.55 & 55.64 & 55.94 & 3.06 & 0.596 & 0.455 & 0.322 \\
\hline Fusobacteria & 0.43 & 0.26 & 0.55 & 1.70 & 0.38 & 0.567 & 0.324 & 0.412 \\
\hline Tenericutes & 0.13 & 0.22 & 0.31 & 0.07 & 0.03 & 0.092 & 0.389 & 0.023 \\
\hline Verrucomicrobia & 0.03 & 0.03 & 0.00 & 0.01 & 0.01 & 0.527 & 0.550 & 0.743 \\
\hline Unclassified-bacteria & 0.12 & 0.14 & 0.16 & 0.14 & 0.01 & 0.823 & 0.765 & 0.580 \\
\hline Unidentified-bacteria & 0.02 & 0.03 & 0.05 & 0.04 & 0.01 & 0.347 & 0.473 & 0.228 \\
\hline
\end{tabular}

MSP, multi-strain probiotic; SEM, standard error of the mean.

1) OMSP, 2MSP, 4MSP, 6MSP: a basal diet with 0, 2, 4, and $6 \mathrm{~g}$ MSP per calf per day, respectively.

and promote their growth [21]. Previous studies have shown that the probiotics can promote the growth of experiencing high incidences of diarrhea calves [22,23], which was similar to our results.

\section{Diarrhea incidence}

The gastrointestinal microflora of newborn calves has not been completely established, which is vulnerable to dietary changes, environmental factors, and other stress, resulting in the destruction of the flora balance, leading to the occurrence of diarrhea [24]. Probiotics entering into the digestive tract of animals can produce various antimicrobial compounds, such as bacteriocins, hydrogen peroxide, volatile fatty acids and nitric oxide, which allows the probiotic bacteria to compete with native or pathogenic species gut bacteria [25]. As a result, the probiotic can enhance the intestinal health by establishing a beneficial gut microbiota and prevent enteric pathogens to infect the intestines of calves [26]. The FCI can reflect the severity of diarrhea in calves. The higher value of FCI means the softer the feces and the more serious of diarrhea. In current study, we found that MSP can effectively prevented diarrhea and reduced the FCI value of calves, in-

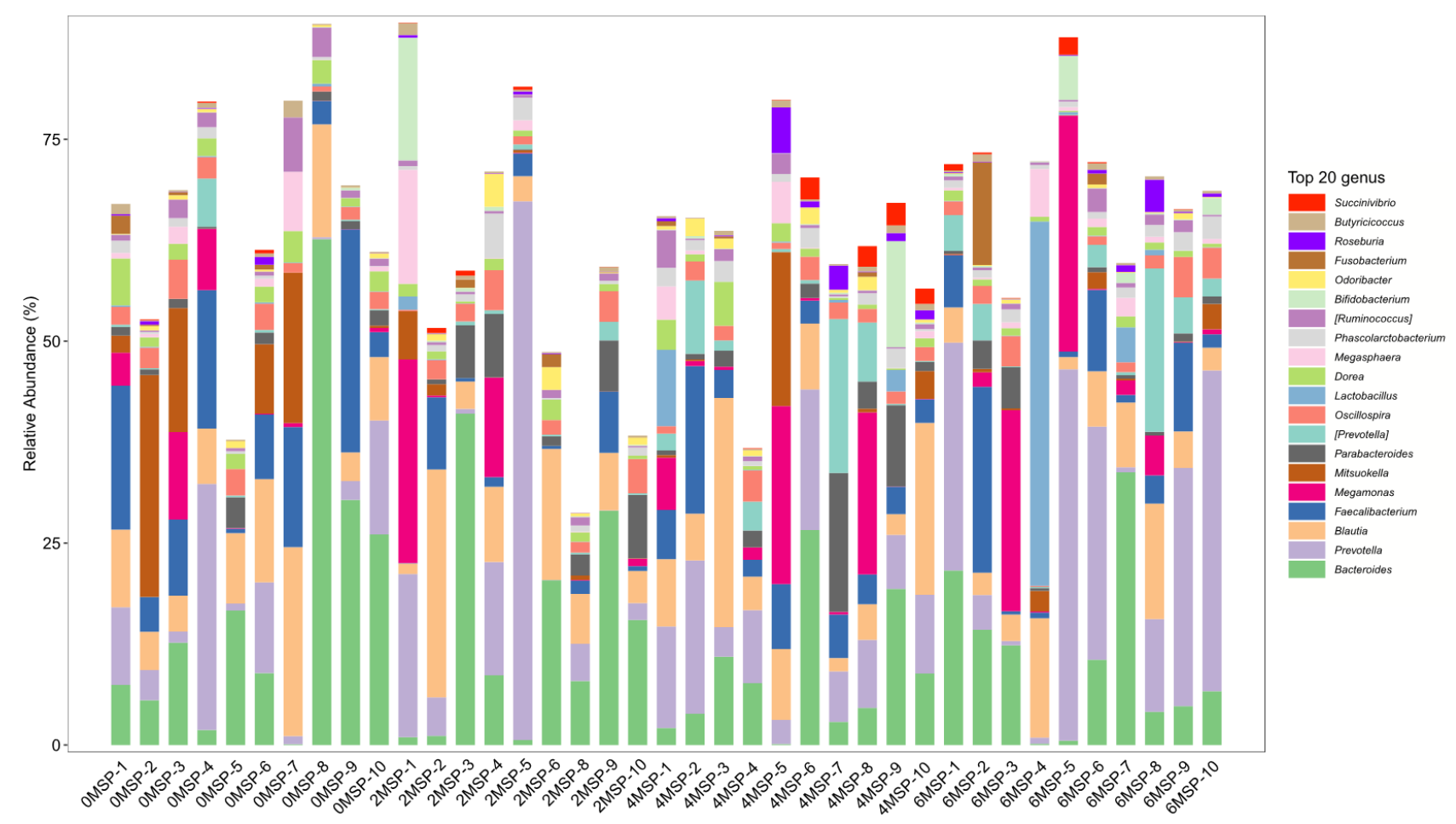

Figure 5. Fecal bacterial flora composition of calves (genus level, \%). OMSP, 2MSP, 4MSP, 6MSP: a basal diet with 0, 2, 4, and $6 \mathrm{~g}$ MSP per calf per day, respectively. MSP, multi-strain probiotic. 
Table 8. Effect of MSP on the relative abundance of fecal bacteria flora of calves (genus level; \%)

\begin{tabular}{|c|c|c|c|c|c|c|c|c|}
\hline \multirow{2}{*}{ Genus name } & \multicolumn{4}{|c|}{ Dietary treatments ${ }^{1)}$} & \multirow{2}{*}{ SEM } & \multicolumn{3}{|c|}{ p-value } \\
\hline & OMSP & 2MSP & 4MSP & 6MSP & & All & Linear & Quad \\
\hline Bifidobacterium & 0.05 & 1.85 & 1.42 & 0.98 & 0.52 & 0.697 & 0.514 & 0.319 \\
\hline Bacteroides & 17.22 & 14.08 & 8.69 & 10.88 & 2.14 & 0.515 & 0.477 & 0.540 \\
\hline Prevotella & 7.50 & 13.59 & 9.58 & 19.01 & 2.36 & 0.273 & 0.058 & 0.708 \\
\hline unidentified-S24-7 & 2.83 & 6.04 & 3.90 & 0.53 & 1.41 & 0.639 & 0.720 & 0.282 \\
\hline unidentified-bacteroidales & 6.54 & 7.27 & 5.87 & 1.61 & 1.23 & 0.269 & 0.173 & 0.260 \\
\hline Dorea & $2.54^{a}$ & $1.07^{b}$ & $1.59^{\mathrm{ab}}$ & $0.82^{b}$ & 0.21 & 0.011 & 0.001 & 0.338 \\
\hline Faecalibacterium & $10.57^{\mathrm{a}}$ & $2.09^{b}$ & $5.62^{\mathrm{ab}}$ & $5.84^{\mathrm{ab}}$ & 1.08 & 0.045 & 0.050 & 0.035 \\
\hline unidentified-ruminococcaceae & 6.09 & 5.30 & 3.47 & 2.81 & 0.69 & 0.326 & 0.209 & 0.963 \\
\hline Megamonas & 2.37 & 3.86 & 5.19 & 6.37 & 1.33 & 0.727 & 0.368 & 0.955 \\
\hline Mitsuokella & 7.26 & 0.79 & 2.36 & 0.88 & 1.01 & 0.106 & 0.030 & 0.233 \\
\hline unidentified-clostridiales & 7.12 & 11.74 & 11.44 & 10.85 & 1.06 & 0.376 & 0.222 & 0.221 \\
\hline
\end{tabular}

MSP, multi-strain probiotic; SEM, standard error of the mean.

1) OMSP, 2MSP, 4MSP, 6MSP: a basal diet with 0, 2, 4, and $6 \mathrm{~g}$ MSP per calf per day, respectively.

$a, b$ Mean values within a row with different superscripts differ significantly (Tukey's test; $p<0.05$ ).

dicating that feeding MSP enhanced gut health and inhibited pathogen growth in the gut. The results of our study are consistent with the results of Casper et al [27], who indicated that the fecal scores were improved linearly with increasing Lactobacillus plantarum inclusion rate $(0,4$, and $8 \mathrm{~g} / \mathrm{d})$ in neonatal calves, and probiotics could changes of the intestinal microflora, thereby helping to improve animal intestinal health and growth performance [28].

\section{Serum metabolites, antioxidant, and immunological parameters}

The serum index can be used to evaluate the metabolic capacity of animal nutrients, antioxidant status and the level of immune response [29]. Blood AST level is an important indicator to evaluate liver function, and elevated AST activity indicates liver dysfunction [30]. In the current study, we found that the concentration of AST in serum tended to decrease as the dosage of MPS increased, which means that MSP has the potential to improve the liver function of calves. Under normal physiological conditions, the production and elimination of free radicals in animals are in a dynamic balance, and excessive free radicals will lead to oxidative stress [31]. TC mainly comes from the metabolic process of the liver, and it is one of the important indexes to evaluate liver lipid metabolism. The increased TC concentration of the calves in the current study, which may be related to a better use of the starter feed intake and TDMI by calves fed with high dosage of MSP. Frizzo et al [11] also reported that the young calves fed with lactic acid bacteria diets had a higher serum TC values than fed with control diets. MDA is the product of lipid peroxidation of cell membrane, and its content can indirectly reflect the production of free radicals and the degree of lipid peroxidation of tissues and cells. The content MDA was numerically lower in serum of 2MSP, 4MSP, and 6MSP calves than the 0MSP calves in the current study, which means that the MSP can improve the serum antioxidant capacity, but the effect is limited.

\section{Microbial composition of feces}

The bacterial phyla in the mammalian gastrointestinal tract are mainly composed of Firmicutes, Bacteroidetes, Actinomycetes, and Proteobacteria, which are vital to the healthy growth of animals [32]. Our study also found that the dominant phyla in the feces of calves were Bacteroidetes, Firmicutes, Actinomycetes, and Proteobacteria, and the relative abundance were $40 \%, 55 \%, 1 \%$ and $1 \%$, respectively. Diet can affect the presence of Tenericutes in the intestinal [33], which tends to be lower in animals feeding with high nutrient diet [34]. With increasing age of animals, the proportion of Tenericutes in gut microbiota increased [35]. In the present research, we found that, the relative abundance of Tenericutes tended to increase as the dosage of MSP increased, this phenomenon may be explained by the fact that the probiotic could manipulate maturation of intestinal microbial communities and nutrient absorption, which implied that the guts of calves with less abundance of Tenericutes was healthier. The dietary MSP did not affect the abundance of others fecal microflora at the phylum level, which in consistent with the results of Ma et al [36], who found that the supplementation of three probiotics, Saccharomyces cerevisiae, Bacillus subtilis, and Enterococcus faecalis, singly or in combination, had no significant effect on the intestinal bacterial abundance or diversity of Sannan dairy goats.

In the current study, we found that the dominant bacteria in the intestinal tract of calves were mainly anaerobic bacteria at the genus level, such as Bacteroides, Prevotella and unclassified-clostridiales, which is consistent with the results of Zhang et al [37]. We also found that dietary MSP stabilized the gut 
microbiota and reduced the risk of pathogen colonization. Prevotella can produce short-chain fatty acids and are able to prevent gastrointestinal tract infection by competing with pathogenic bacteria for binding sites on epithelial cells [21]. Dorea and Mitsuokella are both rumen digestion bacteria, and Dorea is a conditional pathogenic bacteria [38]. The lower Dorea and higher Prevotella in the feces of calves in our study can explain the reduced of diarrhea rates for calves fed with MSP. Similar to our results, Xu et al [38] also reported that the supplementation of probiotics could decrease the Dorea in feces of dairy cows. The relative abundance of Faecalibacterium was lower in calves with the addition of MSP in the current study and in healthy calves in the report of Gomez et al [39], mainly because $F$. prausnitzii has been related to anti-inflammatory properties by stimulating the production of anti-inflammatory cytokines, and reducing the secretion of the pro-inflammatory cytokines by the production of butyrate [40].

\section{CONCLUSION}

Overall, this study demonstrated that MSP product can be used in the milk replacer of neonatal dairy calves to reduce diarrhea, improve the ADG and TDMI under the commercial conditions. The relative abundance of beneficial microflora (Prevotella) in feces tended to increase, and opportunistic pathogens Dorea decreased. The optimal dose was $6 \mathrm{~g} / \mathrm{d}$ per animal based on the growth performance, diarrhea incidence and microflora in feces under the condition of this experiment.

\section{CONFLICT OF INTEREST}

We certify that there is no conflict of interest with any financial organization regarding the material discussed in the manuscript. Qihong Liu is an employee of Jiangsu Hengfengqiang Biotechnology Co., Ltd.

\section{FUNDING}

This work was supported by Guangdong Provincial Promotion Project on Preservation and Utilization of Local Breed of Livestock and Poultry (4300-F18260), and the National Natural Science Foundation of China (31872382 and 31501982).

\section{ACKNOWLEDGMENTS}

We also thank Zhaoqing Wens dairy farm (Zhaoqing, Guangdong, China) for use of their animals and facilities.

\section{REFERENCES}

1. Lyoo K, Jung M, Yoon S, Kim HK, Jeong DG. Identification of canine norovirus in dogs in South Korea. BMC Vet Res 2018;14:413. https://doi.org/10.1186/s12917-018-1723-6

2. Lorenz I, Mee JF, Earley B, More SJ. Calf health from birth to weaning. I. General aspects of disease prevention. Ir Vet J 2011;64:10. https://doi.org/10.1186/2046-0481-64-10

3. Kelsey AJ, Colpoys JD. Effects of dietary probiotics on beef cattle performance and stress. J Vet Behav 2018;27:8-14. https://doi.org/10.1016/j.jveb.2018.05.010

4. Malmuthuge N, Griebel PJ, Guan LL. The gut microbiome and its potential role in the development and function of newborn calf gastrointestinal tract. Front Vet Sci 2015;2:36. https://doi.org/10.3389/fvets.2015.00036

5. Wang Y, Gong L, Wu YP, Cui ZW, Li WF. Oral administration of Lactobacillus rhamnosus GG to newborn piglets augments gut barrier function in pre-weaning piglets. J Zhejiang Univ Sci B 2019;20:180-92. https://doi.org/10.1631/ jzus.B1800022

6. Frizzo LS, Zbrun MV, Soto LP, Signorini ML. Effects of probiotics on growth performance in young calves: A metaanalysis of randomized controlled trials. Anim Feed Sci Technol 2011;169:147-56. https://doi.org/10.1016/j.anifeedsci. 2011.06.009

7. Saleem AM, Zanouny AI, Singer AM. Growth performance, nutrients digestibility, and blood metabolites of lambs fed diets supplemented with probiotics during pre- and postweaning period. Asian-Australas J Anim Sci 2017;30:52330. https://doi.org/10.5713/ajas.16.0691

8. Seo JK, Kim S, Kim MH, Upadhaya SD, Kam DK, Ha JK. Direct-fed microbials for ruminant animals. Asian-Australas J Anim Sci 2010;23:1657-67. https://doi.org/10.5713/ajas.2010. r.08

9. Santillo A, Annicchiarico G, Caroprese M, Marino R, Sevi A, Albenzio M. Probiotics in milk replacer influence lamb immune function and meat quality. Animal 2012;6:33945. https://doi.org/10.1017/S1751731111001571

10. Do Carmo MS, Itapary Dos Santos C, Araújo MC, Girón JA, Fernandes ES, Monteiro-Neto V. Probiotics, mechanisms of action, and clinical perspectives for diarrhea management in children. Food Funct 2018;9:5074-95. https://doi.org/10. 1039/C8FO00376A

11. Frizzo LS, Soto LP, Zbrun MV, et al. Lactic acid bacteria to improve growth performance in young calves fed milk replacer and spray-dried whey powder. Anim Feed Sci Technol 2010; 157:159-67. https://doi.org/10.1016/j.anifeedsci.2010.03.005

12. Taras D, Vahjen W, Simon O. Probiotics in pigs-modulation of their intestinal distribution and of their impact on health and performance. Livest Sci 2007;108:229-31. https://doi. org/10.1016/j.livsci.2007.01.075

13.Lutful Kabir SM. The role of probiotics in the poultry industry. 
Int J Mol Sci 2009;10:3531-46. https://doi.org/10.3390/ijms 10083531

14. Alawneh JI, Barreto MO, Moore RJ, et al. Systematic review of an intervention: the use of probiotics to improve health and productivity of calves. Prev Vet Med 2020;183:105147. https://doi.org/10.1016/j.prevetmed.2020.105147

15.AOAC. Official methods of analysiss. 15th ed. Washington, DC, USA: Association of Official Analytical Chemists; 1990.

16. Khan MA, Lee HJ, Lee WS, et al. Starch source evaluation in calf starter: I. feed consumption, body weight gain, structural growth, and blood metabolites in holstein calves. J Dairy Sci 2007;90:5259-68. https://doi.org/10.3168/jds.2007-0338

17. Marcondes MI, Pereira TR, Chagas JCC, et al. Performance and health of Holstein calves fed different levels of milk fortified with symbiotic complex containing pre -and probiotics. Trop Anim Health Prod 2016;48:1555-60. https://doi.org/ 10.1007/s11250-016-1127-1

18.Sun YY, Li J, Meng QS, Wu DL, Xu M. Effects of butyric acid supplementation of acidified milk on digestive function and weaning stress of cattle calves. Livest Sci 2019;225:78-84. https://doi.org/10.1016/j.livsci.2019.04.021

19. Marchesi JR, Adams DH, Fava F, et al. The gut microbiota and host health: a new clinical frontier. Gut 2016;65:330-9. https:// doi.org/10.1136/gutjnl-2015-309990

20.Sato T, Hidaka Y, Kamimura S. Sugar supplementation stimulates growth performance in calves with growth retardation. J Vet Med Sci 2010;72:29-33. https://doi.org/10.1292/jvms. 09-0180

21.Cangiano LR, Yohe TT, Steele MA, Renaud DL. Invited Review: Strategic use of microbial-based probiotics and prebiotics in dairy calf rearing. Appl Anim Sci 2020;36:630-51. https://doi. org/10.15232/aas.2020-02049

22.Zhang L, Jiang X, Liu X, et al. Growth, health, rumen fermentation, and bacterial community of Holstein calves fed Lactobacillus rhamnosus GG during the preweaning stage. J Anim Sci 2019;97:2598-608. https://doi.org/10.1093/jas/ skz126

23. Timmerman HM, Mulder L, Everts $\mathrm{H}$, et al. Health and growth of veal calves fed milk replacers with or without probiotics. J Dairy Sci 2005;88:2154-65. https://doi.org/10.3168/jds. S0022-0302(05)72891-5

24. Bendali F, Sanaa M, Bichet H, Schelcher F. Risk factors associated with diarrhoea in newborn calves. Vet Res 1999;30: 509-22.

25.Chenoll E, Casinos B, Bataller E, et al. Novel probiotic Bifidobacterium bifidum CECT 7366 strain active against the pathogenic bacterium Helicobacter pylori. Appl Environ Microbiol 2011;77:1335-43. https://doi.org/10.1128/AEM. 01820-10

26. Uyeno Y, Shigemori S, Shimosato T. Effect of probiotics/ prebiotics on cattle health and productivity. Microbes Environ 2015;30:126-32. https://doi.org/10.1264/jsme2.ME14176
27.Casper DP, Hultquist KM, Acharya IP. Lactobacillus plantarum GB LP-1 as a direct-fed microbial for neonatal calves. J Dairy Sci 2021;104:5557-68. https://doi.org/10.3168/jds. 2020-19438

28. Jiang Z, Wei S, Wang Z, et al. Effects of different forms of yeast Saccharomyces cerevisiae on growth performance, intestinal development, and systemic immunity in earlyweaned piglets. J Anim Sci Biotechnol 2015;6:47. https:// doi.org/10.1186/s40104-015-0046-8

29.Jiao LF, Ke YL, Xiao K, Song ZH, Hu CH, Shi B. Effects of cello-oligosaccharide on intestinal microbiota and epithelial barrier function of weanling pigs. J Anim Sci 2015;93:115764. https://doi.org/10.2527/jas.2014-8248

30.Gu XL, Li H, Song ZH, Ding YN, He X, Fan ZY. Effects of isomaltooligosaccharide and Bacillus supplementation on sow performance, serum metabolites, and serum and placental oxidative status. Anim Reprod Sci 2019;207:52-60. https:// doi.org/10.1016/j.anireprosci.2019.05.015

31.Lykkesfeldt J, Svendsen O. Oxidants and antioxidants in disease: oxidative stress in farm animals. Vet J 2007;173:502-11. https:// doi.org/10.1016/j.tvjl.2006.06.005

32. Shanks OC, Kelty CA, Archibeque S, et al. Community structures of fecal bacteria in cattle from different animal feeding operations. Appl Environ Microb 2011;77:2992-3001. https:// doi.org/10.1128/AEM.02988-10

33. Buzoianu SG, Walsh MC, Rea MC, et al. High-throughput sequence-based analysis of the intestinal microbiota of weanling pigs fed genetically modified MON810 maize expressing Bacillus thuringiensis Cry1 Ab (Bt maize) for 31 days. Appl Environ Microb 2012;78:4217-24. https://doi. org/10.1128/aem.00307-12

34.Ji Y, Kong X, Li H, Zhu Q, Guo Q, Yin Y. Effects of dietary nutrient levels on microbial community composition and diversity in the ileal contents of pregnant Huanjiang minipigs. Plos One 2017;12:e0172086. https://doi.org/10.1371/ journal.pone.0172086

35.Niu Q, Li P, Hao S, et al. Dynamic distribution of the gut microbiota and the relationship with apparent crude fiber digestibility and growth stages in pigs. Sci Rep-Uk 2015;5: 9938. https://doi.org/10.1038/srep09938

36. Ma ZZ, Cheng YY, Wang SQ, Ge JZ, Shi HP, Kou JC. Positive effects of dietary supplementation of three probiotics on milk yield, milk composition and intestinal flora in Sannan dairy goats varied in kind of probiotics. J Anim Physiol Anim Nutr 2020;104:44-55. https://doi.org/10.1111/jpn.13226

37.Zhang J, Xu C, Huo D, Hu Q, Peng Q. Comparative study of the gut microbiome potentially related to milk protein in Murrah buffaloes (Bubalus bubalis) and Chinese Holstein cattle. Sci Rep-Uk 2017;7:42189. https://doi.org/10.1038/ srep42189

38.Xu H, Huang W, Hou Q, et al. The effects of probiotics administration on the milk production, milk components and fecal 
bacteria microbiota of dairy cows. Sci Bull (Beijing) 2017;62: 767-74. https://doi.org/10.1016/j.scib.2017.04.019

39. Gomez DE, Arroyo LG, Costa MC, Viel L, Weese JS. Characterization of the fecal bacterial microbiota of healthy and diarrheic dairy calves. J Vet Intern Med 2017;31:928-39. https://doi.org/10.1111/jvim.14695

40. Foditsch C, Santos TM, Teixeira AG, et al. Isolation and characterization of Faecalibacterium prausnitzii from calves and piglets. Plos One 2014;9:e116465. https://doi.org/10.1371/ journal.pone.0116465 